\title{
Correction to: The Consequences of Explicit and Implicit Gender Attitudes and Candidate Quality in the Calculations of Voters
}

\section{Cecilia Hyunjung Mo ${ }^{1}$}

\section{Correction to: Polit Behav (2015) 37:357-395 DOI 10.1007/s11109-014-9274-4}

The original version of this article contains a labelling mistake. Table 3 reports the quality score by ABA Rating. The order of the labels under "Weak ranking" in Table 3 is incorrect. The correction strengthens the claim in the article that the study participants were more likely to assign higher likability score to candidates with objectively better ABA ratings. The corrected Table 3 is given below.

The online version of the original article can be found under doi:10.1007/s11109-014-9274-4.

Cecilia Hyunjung Mo

cecilia.h.mo@vanderbilt.edu

1 Department of Political Science, Vanderbilt University, PMB 0505, 230 Appleton Place, Nashville, TN 37203-5721, USA 
Table 3 Candidate ABA ratings

\begin{tabular}{ll}
\hline ABA rating & Quality score \\
\hline Strong ranking & \\
Well qualified & 4.84 \\
Well qualified (substantial majority)/qualified (minority) & 4.73 \\
Well qualified (majority)/qualified (minority) & 4.78 \\
Qualified & 4.69 \\
Weak ranking & \\
Qualified (substantial majority)/not qualified (minority) & 4.22 \\
Qualified (majority)/not qualified (minority) & 4.20 \\
Qualified (minority)/not qualified (majority) & 4.10 \\
Qualified (minority)/not qualified (substantial majority) & 4.11 \\
Not qualified & 3.92 \\
\hline
\end{tabular}

